\title{
Blood pressure, cardiorespiratory fitness and body mass: Results from the Tromsø Activity Study
}

\author{
Aina Emaus, ${ }^{1}$ Tom Wilsgaard, ${ }^{2}$ Anne-Sofie Furberg ${ }^{2,3}$ and Inger Thune ${ }^{1}$ \\ 1) Department of Oncology, Oslo University Hospital, Ullevål, Norway \\ 2) Department of Community Medicine, Faculty of Health Sciences, University of Tromsø, Norway \\ 3) Department of Microbiology and Infection Control, University Hospital North Norway, Norway
}

Correspondence: Aina Emaus, e-mail: aina.emaus@medisin.uio.no

\begin{abstract}
Aims: Modifiable lifestyle factors, as cardiorespiratory fitness (CRF) and body mass, may prevent hypertension. However, it remains unclear whether blood pressure is associated with CRF, independently of body mass index (BMI). Thus, the purpose was to study the relationship between CRF, body composition and blood pressure among 40-44 year old men and women.

Methods: During 2007-2008, 12,900 men and women aged 30-85 years attended the sixth survey of the Tromsø study. Blood pressure $(\mathrm{mm} \mathrm{Hg})$, height $(\mathrm{cm})$ and weight $(\mathrm{kg})$ were measured and body mass index $\left(\mathrm{BMI} \mathrm{kg} / \mathrm{m}^{2}\right)$ was estimated. In a sub-study, the Tromsø Activity Study, CRF $\left[\mathrm{VO}_{2 \max }(\mathrm{ml} / \mathrm{kg} / \mathrm{min})\right]$ was objectively measured using a treadmill test among 313 healthy men and women aged 40-44 years.

Results: Among men and women participating in both studies, the mean BMI was $27.1 \mathrm{~kg} / \mathrm{m}^{2}$ for men and $25.1 \mathrm{~kg} / \mathrm{m}^{2}$ for women. Mean arterial blood pressure (MAP) was $92.4 \mathrm{~mm} \mathrm{Hg}$ for men and $86.0 \mathrm{~mm} \mathrm{Hg}$ for women. The proportion defined as pre-hypertensive/hypertensive (systolic/diastolic blood pressure $>120 / 80$ ) were $33 \%$ and $56 \%$ for women and men, respectively. The proportion of low, medium and high CRF for both sexes combined differed significantly $(p<0.0001)$ by BMI level $\left(<25\right.$ or $\left.\geq 25 \mathrm{~kg} / \mathrm{m}^{2}\right)$. Increased fitness tended to reduce blood pressure among overweight and obese men ( $\mathrm{p}$ trend $=0.03)$, whereas increased fitness tended to reduce blood pressure among normal weighted women $(\mathrm{p}$ trend $=0.01)$.

Conclusion: Among healthy 40-44 year old men and women in this study, BMI was positively associated and CRF was negatively associated with blood pressure. Moreover, our results suggest that BMI may be a more important factor than CRF in predicting systolic blood pressure in both sexes. However, cardiorespiratory fitness and weight control may both be important targets for prevention of hypertension.
\end{abstract}

\section{INTRODUCTION}

Hypertension is one of the most common medical disorders and data from observational studies have demonstrated increasing risk of stroke, myocardial infarction, cardiovascular death, site specific cancer and all cause mortality associated with high blood pressure (1-3).

High levels of leisure-time physical activity have been associated with a reduced risk of hypertension, independently of most common risk factors for hypertension (4). Additionally, higher levels of cardiorespiratory fitness (CRF), defined as maximal achieved exercise capacity, have shown to be associated with reduced risk of developing hypertension among healthy normo-tensive persons and higher incidences of hypertension have been demonstrated among individuals with low fitness compared with fit individuals (5-7). Moreover, evidence from randomized controlled studies shows that exercise (both endurance and resistance exercise) has favorable effects on blood pressure (8).

However, not only physical activity and CRF, but also other lifestyle factors are associated with hypertension, most notably obesity $(9,10)$. Obesity is also linked to other chronic diseases and metabolic disor- ders (11). Cross sectional and observational studies have documented a positive association between blood pressure and body weight (12) and blood pressure increases over time among subjects who experience weight gain (13).

The prevalence of obesity and obesity-related diseases is increasing worldwide. Availability of high fat, energy-dense food, large portion sizes and low cost of fast food are main contributors to the observed increased energy intake (14). A decline in work related physical activity, and increase in sedentary behavior in all types of daily living activities have been observed and these changes tend to drive down daily energy expenditure values (14). A review of secular trends suggests that the prevalence of obesity is more strongly related to decreases in energy expenditure than to increases in energy intake (15). A recent Cochrane review supports the use of exercise as a target for weight loss, particularly when combined with dietary change, and this review also found that exercise improved health even if no weight is lost (16).

The proposed mechanisms for the blood pressure lowering effects of exercise include neurohumoral, vascular, and structural adaptations (17). Decreases in catecholamines and total peripheral resistance, im- 
proved insulin sensitivity, and alterations in vasodilators and vasoconstrictors are some of the postulated explanations for the antihypertensive effects of exercise (17). Thus, it is likely that the lowering of blood pressure by exercise is multifactorial and further studies are needed to elucidate the mechanism (18).

A general assumption is that overweight or obese individuals probably are physically inactive and unfit, and that lean individuals probably are physically active and fit. According to conclusions performed by experts in the area $(19,20)$, available evidence suggests that overweight and obese adults who achieve adequate levels of physical activity or CRF, have lower risk of total and cardio-vascular morbidity and mortality than do their normal-weight, but sedentary or unfit peers.

A key unanswered question is whether improvement of CRF, independently of changes in body mass index (BMI), is a more important first target for prevention of hypertension than reduction in BMI. This has significant implications for health-care providers and patients in creating the most effective first strategies to achieve optimal blood pressure control.

On this background, the main purpose of this study was to examine the relationship between CRF, body composition and blood pressure among 40-44 year old men and women participating in the Tromsø Activity Study.

\section{MATERIAL AND METHODS}

\section{Study population}

Detailed information on the development and followup of the Tromsø Activity Study has been reported previously (21). In brief, the study subjects were recruited among men and women who participated in the sixth population-based health screening survey of the Tromsø Study carried out in 2007-2008. Baseline information was obtained from clinical examinations and questionnaires, including history of chronic diseases and physical activity. A sample of 746 male and female participants aged 40-44 years were invited by mail to the Tromsø Activity Study in 2008-2009. The participants were randomly selected from those who attended during the last months of the core examination of the sixth Tromsø Study (Sept to Dec 2008), 391 (52\%) persons responded, and 313 persons were eligible to participate. The mean time interval between the measurements in the screening survey and the Activity Study was 3.2 months.

Each subject gave written informed consent prior to participation. The Regional Committee of Medical and Health Research Ethics recommended the protocol, and the Norwegian Data Inspectorate approved the study.

\section{Anthropometric measurements and blood pressure}

Antropometric measurements were assessed in the screening survey with participants wearing light clothing and no footwear. Height was measured to the nearest half-centimeter and weight to the nearest 0.1 $\mathrm{kg}$ on an automatic electronic scale Jenix DS 102 stadiometer (Dong Sahn Jenix Co., Ltd., Seoul, Korea). BMI was calculated as a measure of body mass relative to height $\left(\mathrm{kg} / \mathrm{m}^{2}\right)$. Waist circumference was measured in a horizontal line $2.5 \mathrm{~cm}$ above umbilicus, hip circumference was measured at the largest circumference and both were measured to the nearest $0.5 \mathrm{~cm}$. Waist-to-hip ratio (WHR) was estimated.

Blood pressure was measured when the participants were sitting (automated device Dinamap Pro care 300 Monitor). Three readings were taken, separated with a one minute interval. The mean of the two latest blood pressure readings was used in the present study.

\section{Physical fitness assessments}

To assess CRF, the participants in the Tromsø Activity Study completed an incremental $\mathrm{VO}_{2 \max }$ test performed until total exhaustion, administered by two trained study assistants (21). $\mathrm{VO}_{2 \max }$ is defined as the highest rate of oxygen consumption attainable during maximal exercise. Normally aerobic power $\left(\mathrm{VO}_{2 \max }\right)$ is expressed by dividing measured values by body mass $(\mathrm{ml} / \mathrm{kg} / \mathrm{min})$ making it possible to compare the fitness level between individuals of different body mass. The beginning pace varied by individual, starting with a speed that elicited a heart rate of approximately 145 beats/min. Since running technique differs, participants could choose if they preferred having speed increased, level of incline increased, or a combination of both to enhance workload. Every minute the workload was increased $(1 \mathrm{~km} / \mathrm{h}$ or two grades incline increments). Towards the end of the test, workload was increased individually to motivate test subjects to continue when changing to a heavier stage. Heart rate was monitored with a Polar S 610 I (Finland) wrist watch. Expired air was analyzed continuously for $\mathrm{O}_{2}$ and carbon-dioxide $\left(\mathrm{CO}_{2}\right)$ by an Erich Jaguar Oxycon Pro (Jaeger-Viasys Healthcare, Hoechberg, Germany) oxygen analyzer, calibrated with standardized gases before each test. The subjects breathed through a Hans Rudolph valve (2700 series) with registration of ventilation, $\mathrm{VO}_{2}, \mathrm{CO}_{2}$, and respiratory exchange ratio $\left(\mathrm{VCO}_{2} / \mathrm{VO}_{2}, \mathrm{RER}\right)$ at 30 seconds averages.

Subjects had to achieve at least one of the two following criteria; 1) the ability to demonstrate a $\mathrm{VO}_{2}$ plateau, defined as a failure of oxygen uptake to increase by greater than $2.0 \mathrm{ml} / \mathrm{kg} / \mathrm{min}$ with increasing treadmill speed/incline, 2) respiratory exchange ratio $(\mathrm{RER}) \geq 1.05$. In addition, the test-administrator evaluated the following characteristics of maximal performance: Test subject expressed orally or in terms of body language, that he or she was totally exhausted or the test subject could not continue to run properly, was blanching and in danger of falling due to exhaustion. The highest oxygen uptake reached $(30$ seconds average) was recorded as $\mathrm{VO}_{2 \max }$.

\section{Classification strategies and statistical analyses}

BMI was stratified into two groups $(<25$ and $\geq 25$ $\mathrm{kg} / \mathrm{m}^{2}$ ). CRF levels were categorized into sex-specific tertiles; low fitness, $\mathrm{CRF} \mathrm{I}=\mathrm{VO}_{2 \max }<32.4 \mathrm{ml} / \mathrm{kg} / \mathrm{min}$ 
for women and $<39.6 \mathrm{ml} / \mathrm{kg} / \mathrm{min}$ for men; medium fitness, CRF II $=\mathrm{VO}_{2 \max }=32.4-37.5 \mathrm{ml} / \mathrm{kg} / \mathrm{min}$ for women and 39.6-46.5 $\mathrm{ml} / \mathrm{kg} / \mathrm{min}$ for men, and high fitness, CRF III $=\mathrm{VO}_{2 \max }>37.5 \mathrm{ml} / \mathrm{kg} / \mathrm{min}$ for women and $>46.5 \mathrm{ml} / \mathrm{kg} / \mathrm{min}$ for men.

Mean arterial blood pressure (MAP) was estimated as $[($ diastolic blood pressure * 2$)+$ systolic blood pressure $] / 3$, the average arterial pressure during a single cardiac cycle.

Means and standard deviations or frequencies and percentages were used to describe the characteristics of the study participants (Table 1).

In order to study the relationship between CRF, body composition and blood pressure among 40-44 year old men and women participating in the Tromsø Activity Study in detail, multivariable linear regression models were used to estimate changes in blood pressure by one standard deviation increase in CRF and BMI (Table 2). Analyses of variance were used to assess the potential effect of fitness (three groups) on blood pressure in two groups of BMI (Table 3), and trends were estimated using regression models.

Data analyses were conducted using SAS version 9.2 (SAS Institute, Inc., Cary, NC).

Table 1. Descriptive characteristics of men and women, the Tromsø Activity studya. Values are means (SDs) or numbers (percentages).

\begin{tabular}{|c|c|c|}
\hline & $\begin{array}{c}\text { Men } \\
(\mathrm{n}=155)\end{array}$ & $\begin{array}{l}\text { Women } \\
(\mathrm{n}=158)\end{array}$ \\
\hline \multicolumn{3}{|l|}{ Demographics } \\
\hline Age, years & $42.1(1.41)$ & $42.3(1.38)$ \\
\hline Higher education, n (\%) & $85(54.8)$ & $100(63.3)$ \\
\hline \multicolumn{3}{|l|}{ Anthropometric characteristics } \\
\hline Weight, kg & $87.3(13.8)$ & $68.6(10.7)$ \\
\hline Height, cm & $179.5(6.76)$ & $165.4(5.96)$ \\
\hline BMI, $\mathrm{kg} / \mathrm{m}^{2}$ & $27.1(3.66)$ & $25.1(3.82)$ \\
\hline Waist circumference, $\mathrm{cm}$ & $95.8(10.4)$ & $86.4(10.7)$ \\
\hline Waist-to-hip ratio & $0.92(0.06)$ & $0.86(0.06)$ \\
\hline \multicolumn{3}{|l|}{ Blood pressure } \\
\hline Systolic blood pressure, $\mathrm{mm} \mathrm{Hg}$ & $124.2(13.6)$ & $115.5(13.4)$ \\
\hline Diastolic blood pressure, $\mathrm{mm} \mathrm{Hg}$ & $76.5(8.88)$ & $71.2(8.90)$ \\
\hline Mean arterial pressure $\left(\mathrm{MAP}^{\mathrm{b}}\right)$ & $92.4(9.68)$ & $86.0(9.74)$ \\
\hline Pre- /hypertensive ${ }^{\mathrm{c}}, \mathrm{n}(\%)$ & $87(56.1)$ & $52(32.9)$ \\
\hline Hypertensive $^{\mathrm{d}}, \mathrm{n}(\%)$ & $23(14.8)$ & $14(8.86)$ \\
\hline Heart rate, beats $/ \mathrm{min}$ & $63.2(10.6)$ & $64.4(10.5)$ \\
\hline Blood pressure medication, $\mathrm{n}(\%)$ & $7(5.52)$ & 0 \\
\hline Lipid lowering medication, n (\%) & $4(2.58)$ & 0 \\
\hline \multicolumn{3}{|l|}{ Aerobic fitness } \\
\hline $\mathrm{VO}_{2} \max , \mathrm{ml} / \mathrm{kg} / \mathrm{min}$ & $43.2(7.66)$ & $35.5(6.45)$ \\
\hline $\mathrm{VO}_{2} \max , 1 / \min$ & $3.66(0.56)$ & $2.35(0.36)$ \\
\hline \multicolumn{3}{|c|}{$\begin{array}{l}\text { a } 40-44 \text { years. SD, standard deviation. Numbers may vary due to } \\
\text { missing information. }\end{array}$} \\
\hline \multicolumn{3}{|c|}{$\begin{array}{l}{ }^{\mathrm{b}} \mathrm{MAP}=[(\text { Diastolic blood pressure } * 2)+\text { Systolic blood } \\
\text { pressure }] / 3 .\end{array}$} \\
\hline \multicolumn{3}{|c|}{$\begin{array}{l}{ }^{\mathrm{c}} \text { Pre-/ hypertensive: Systolic blood pressure }>120 \text { and / or Diastolic } \\
\text { blood pressure }>80 \mathrm{~mm} \mathrm{Hg} \text {. }\end{array}$} \\
\hline \multicolumn{3}{|c|}{$\begin{array}{l}\text { d Hypertensive: Systolic blood pressure }>140 \text { and / or Diastolic } \\
\text { blood pressure }>90 \mathrm{~mm} \mathrm{Hg} \text {. }\end{array}$} \\
\hline
\end{tabular}

\section{RESUlts}

All together, 158 women and 155 men participated in the Tromsø Activity Study. The sex-specific characteristics of the participants are presented in Table 1 . Mean age was 42.1 years for men and 42.3 years for women, and mean BMI was $27.1 \mathrm{~kg} / \mathrm{m}^{2}$ for men and $25.1 \mathrm{~kg} / \mathrm{m}^{2}$ for women. On average, MAP was 92.4 $\mathrm{mm} \mathrm{Hg}$ for men and $86.0 \mathrm{~mm} \mathrm{Hg}$ for women, and CRF was $43.2 \mathrm{ml} / \mathrm{kg} / \mathrm{min}$ and $35.5 \mathrm{ml} / \mathrm{kg} / \mathrm{min}$ for men and women, respectively. Among the participants, 87 men (56.1\%) and 52 women $(32.9 \%)$ were classified as prehypertensive/ hypertensive with a systolic blood pressure $>120 \mathrm{~mm} \mathrm{Hg}$ and/or a diastolic blood pressure $>$ $80 \mathrm{~mm} \mathrm{Hg}$. While none of the participating women used antihypertensive medication, $5.5 \%$ of men used such medication (Table 1).

The sex specific distribution of CRF level (in tertiles) within BMI level $\left(<25\right.$ or $\left.\geq 25 \mathrm{~kg} / \mathrm{m}^{2}\right)$, are presented in Figure 1. For men, the proportion of subjects with high CRF level (CRF III) was 41 percentage points lower in overweight/obese men (BMI $\geq 25 \mathrm{~kg} / \mathrm{m}^{2}$ ) compared to normal weighted/lean men (BMI $<25$ $\left.\mathrm{kg} / \mathrm{m}^{2}\right)(18 \%$ versus $59 \%)$. The proportion of low CRF level (CRF I) was 42 percentage points higher in overweight/obese men compared to leaner men $49 \%$ versus $7 \%$ ). For women, the proportion of subjects with high CRF level (CRF III) was 32 percentage points lower in overweight/obese women (BMI $\geq 25 \mathrm{~kg} / \mathrm{m}^{2}$ ) compared to normal weighted/lean women (BMI $<25 \mathrm{~kg} / \mathrm{m}^{2}$ ) (15\% versus $47 \%$ ), whereas the proportion of low CRF level (CRF I) was 34 percentage points higher in overweight/obese women compared to leaner women $(52 \%$ versus $18 \%$ ). Approximately $18 \%$ of men and $15 \%$ of women were characterized as fit and fat (BMI $\geq 25$ $\mathrm{kg} / \mathrm{m}^{2}$ and $\mathrm{CRF}>46.5 \mathrm{ml} / \mathrm{kg} / \mathrm{min}$ for men and $>37.5$ $\mathrm{ml} / \mathrm{kg} / \mathrm{min}$ for women). In comparison, $7 \%$ of men and $18 \%$ of women were characterized as normal weighted/lean and in the lowest fitness group (BMI $<25$ $\mathrm{kg} / \mathrm{m}^{2}$ and $\mathrm{CRF}<39.6 \mathrm{ml} / \mathrm{kg} / \mathrm{min}$ for men and $<32.4$ $\mathrm{ml} / \mathrm{kg} / \mathrm{min}$ for women, Figure 1).

Figure 2 presents sex-specific blood pressure (systolic, diastolic and MAP) in three groups of BMI $(<25$, $25-30$ and $\geq 30 \mathrm{~kg} / \mathrm{m}^{2}$ ) and in tertiles of CRF (I-III). Among men, systolic blood pressure, diastolic blood pressure and MAP increased with increasing BMI. On average, men with low CRF level had higher blood pressures than men with higher CRF levels (II-III), but being in the highest CRF level was not associated with further decrease in blood pressures compared to being in the medium CRF level. Among women, systolic blood pressure and MAP increased with increasing BMI, and systolic blood pressure, diastolic blood pressure, and MAP decreased with increasing CRF level.

The strength of an association between BMI and CRF in relation to different measures of blood pressure is presented in Table 2. For men and women, using age-adjusted linear regression models, we found both CRF and BMI to be associated with systolic blood pressure, diastolic blood pressure and MAP (CRF 


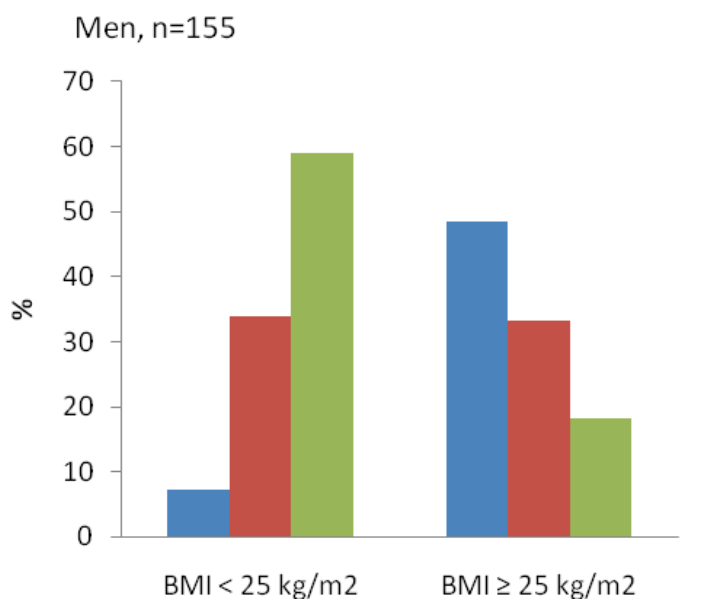

Women, $\mathrm{n}=158$

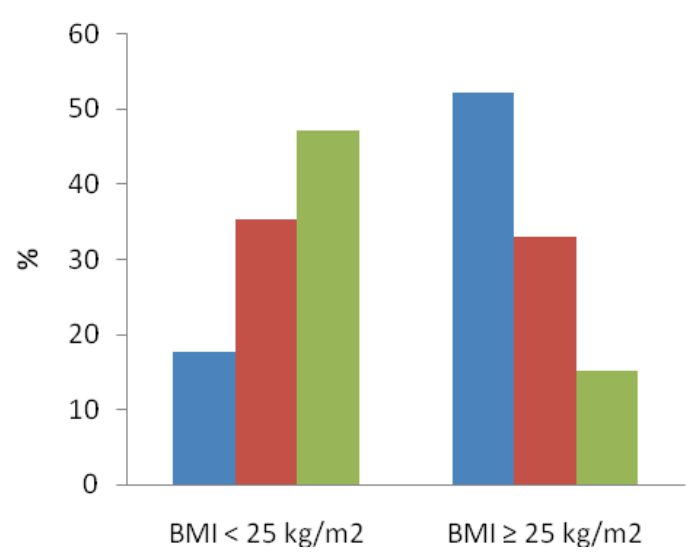

- Low fitness, CRF I

Medium fitness, CRF ॥

- High fitness, CRF III
- Low fitness, CRF I

nedium fitness, CRF II

n High fitness, CRF III

Figure 1. Distribution of cardiovascular fitness level within levels of body mass index (BMI, $\left.\mathrm{kg} / \mathrm{m}^{2}\right)$. The Tromsø Activity Study. Cardiovascular fitness level was categorized in low fitness, CRF I, $\mathrm{VO}_{2} \max <32.4 \mathrm{ml} / \mathrm{kg} / \mathrm{min}$ for women and $<39.6 \mathrm{ml} / \mathrm{kg} / \mathrm{min}$ for men; medium fitness, CRF II, $\mathrm{VO}_{2} \max =32.4-37.5 \mathrm{ml} / \mathrm{kg} / \mathrm{min}$ for women and 39.6-46.5 $\mathrm{ml} / \mathrm{kg} / \mathrm{min}$ for men and high fitness, CRF III, $\mathrm{VO}_{2} \max >37.5 \mathrm{ml} / \mathrm{kg} / \mathrm{min}$ for women and $>46.5 \mathrm{ml} / \mathrm{kg} / \mathrm{min}$ for men.

$\mathrm{p}<0.02$ for both sexes; BMI $\mathrm{p}<0.002$ for both sexes, Model 1). When including both CRF and BMI in the regression model (Model 2), CRF remained negatively associated only with diastolic blood pressure $(\mathrm{p}=0.03)$ and MAP $(p=0.03)$ among women, while there was a pattern of an inverse association for MAP $(p=0.07)$ among men.

Table 3 presents systolic blood pressure, diastolic blood pressure, and MAP according to BMI $(<25$ or $\geq$ $25 \mathrm{~kg} / \mathrm{m}^{2}$ ) and CRF level (in tertiles) for men and women, separately. Fitness was negatively related to blood pressure ( $\mathrm{p}$ trend 0.02 for diastolic blood pressure, 0.04 for systolic blood pressure, and 0.02 for MAP) among overweight and obese men (BMI $\geq 25$ $\mathrm{kg} / \mathrm{m}^{2}$ ), whereas fitness was negatively related ( $\mathrm{p}$ trend 0.005 for diastolic BP, 0.008 for systolic BP and 0.003 for MAP) to blood pressure among lean and normal weighted women $\left(\mathrm{BMI}<25 \mathrm{~kg} / \mathrm{m}^{2}\right.$ ).

\section{DISCUSSION}

Among the healthy 40-44 year old men and women in this study, we found a different distribution of cardio- vascular fitness among normal weighted/lean and overweight/obese participants. In sex-specific age-adjusted analyses, both BMI and CRF were associated with blood pressure. Moreover, high fitness level was more often observed among normal weighted/lean compared to overweight/obese men and women, and our results suggest that BMI may be a more important factor than $\mathrm{CRF}$ in predicting systolic blood pressure.

We observed a higher proportion of high fitness among the normal weighted/lean men and women than among overweight/obese men and women. Other cross sectional studies have found lower prevalence of obesity to be associated with higher level of physical activity $(22,23)$. The association between fitness and BMI observed in our study is cross sectional, and thus causality cannot be elaborated. Thus, low fitness can be both a cause and a consequence of overweight/obesity. High BMI has been associated with subsequent physical inactivity (24) and reduced physical activity may be the main determinant of the rising prevalence of obesity worldwide (25), and the ideal is to be normalweight and physically fit and active (26).

Epidemiological studies have shown that exercise 
Men

BMI
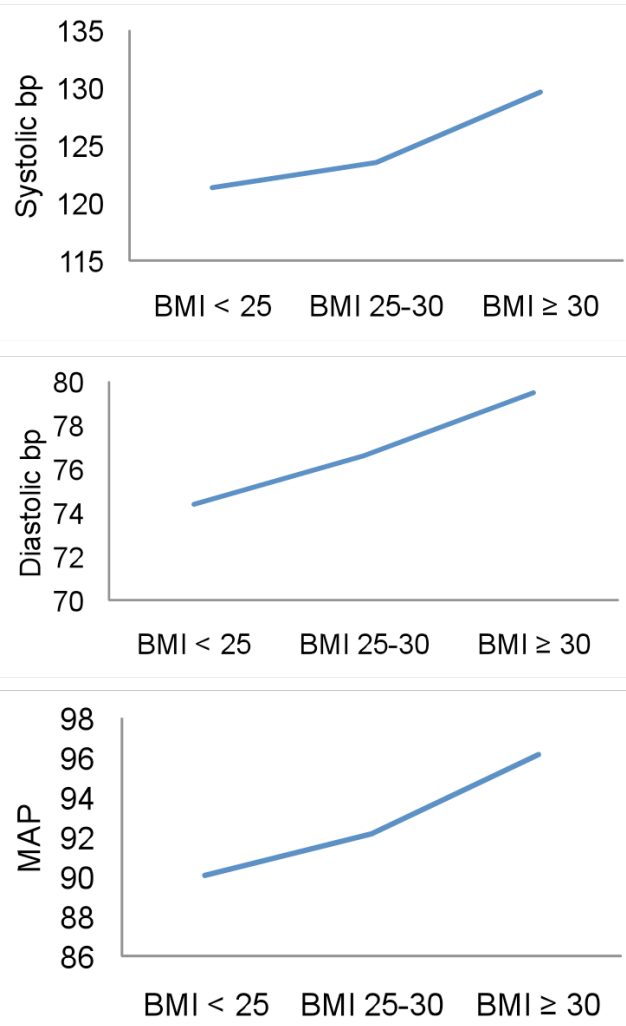

Women
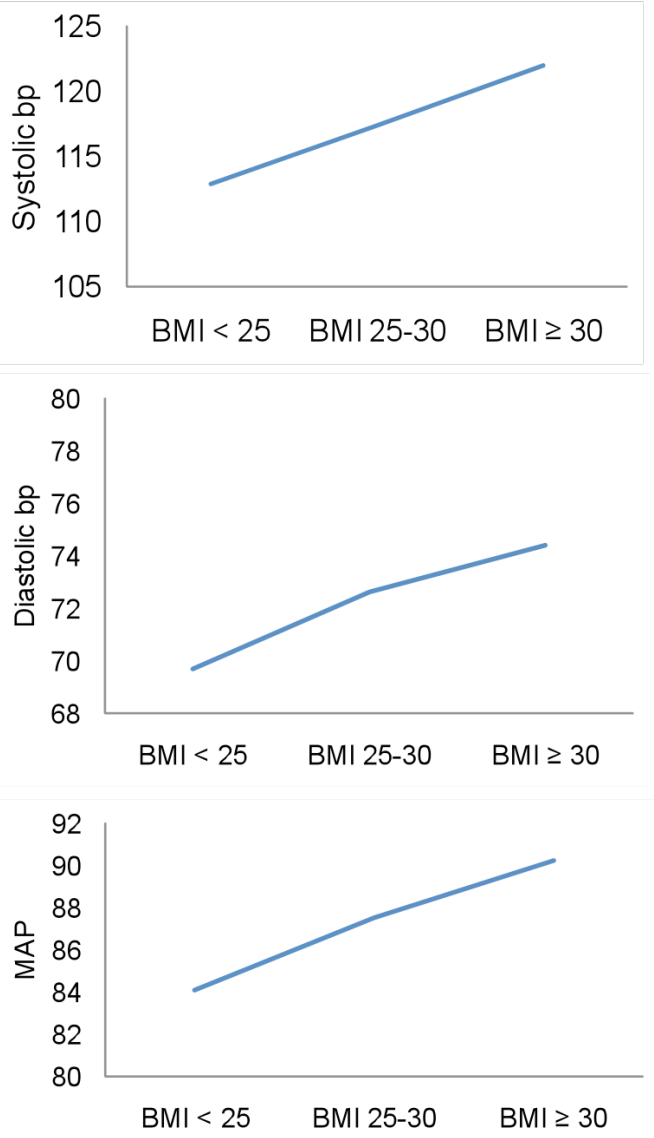
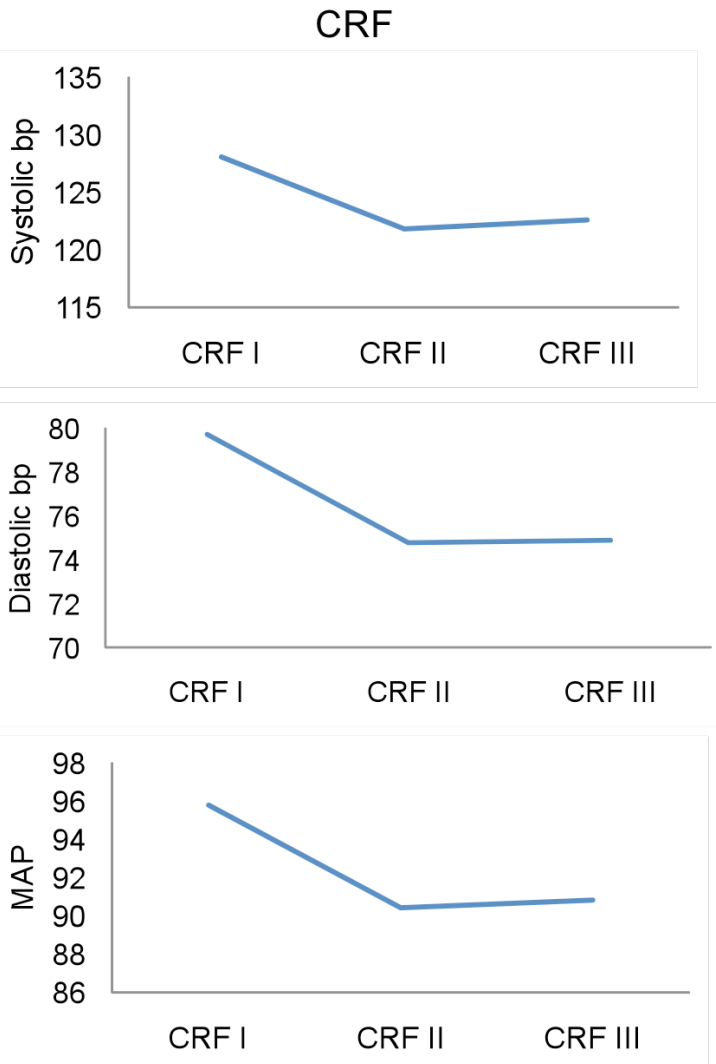

CRF
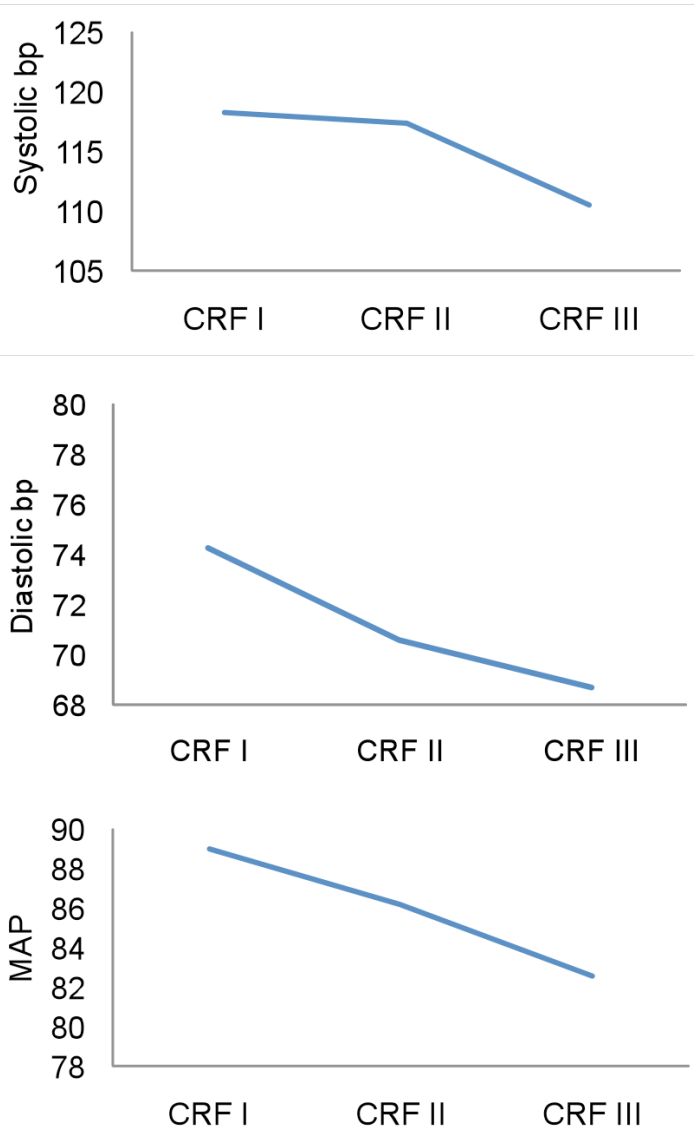

Figure 2. Blood pressure (systolic, diastolic and MAP) in groups of BMI $\left(\mathrm{kg} / \mathrm{m}^{2}\right)$ and cardiovascular fitness (CRF) categorized in low fitness, CRF I, $\mathrm{VO}_{2} \max <32.4 \mathrm{ml} / \mathrm{kg} / \mathrm{min}$ for women and $<39.6 \mathrm{ml} / \mathrm{kg} / \mathrm{min}$ for men; medium fitness, CRF II, $\mathrm{VO}_{2} \max =32.4-37.5 \mathrm{ml} / \mathrm{kg} / \mathrm{min}$ for women and 39.6-46.5 ml $/ \mathrm{kg} / \mathrm{min}$ for men and high fitness, CRF III, $\mathrm{VO}_{2} \max >37.5 \mathrm{ml} / \mathrm{kg} / \mathrm{min}$ for women and $>46.5 \mathrm{ml} / \mathrm{kg} / \mathrm{min}$ for men. 
Table 2. Estimated changes in blood pressure (systolic, diastolic and $\mathrm{MAP}^{\mathrm{a}} ; \mathrm{mm} \mathrm{Hg}$ ) by one standard deviation increase in $\mathrm{CRF}^{\mathrm{b}}$ and $\mathrm{BMI}^{\mathrm{c}}$. Multivariable linear regression models. The Tromsø Activity Study.

\begin{tabular}{|c|c|c|c|c|c|}
\hline & & \multicolumn{2}{|c|}{ Model $1^{\mathrm{d}}$} & \multicolumn{2}{|c|}{ Model $2^{\mathrm{e}}$} \\
\hline & & $\beta$ coeff & $p$ & $\beta$ coeff & $p$ \\
\hline \multicolumn{6}{|l|}{ Women, $n=158$} \\
\hline \multirow[t]{3}{*}{ Systolic blood pressure } & $\mathrm{CRF}(\mathrm{ml} / \mathrm{kg} / \mathrm{min})$ & -3.65 & 0.0006 & -2.04 & 0.11 \\
\hline & BMI $\left(\mathrm{kg} / \mathrm{m}^{2}\right)$ & 3.98 & 0.0002 & 2.82 & 0.03 \\
\hline & & & & P int & 0.86 \\
\hline \multirow[t]{3}{*}{ Diastolic blood pressure } & CRF (ml/kg/min) & -2.44 & 0.0005 & -1.89 & 0.03 \\
\hline & BMI $\left(\mathrm{kg} / \mathrm{m}^{2}\right)$ & 2.04 & 0.004 & 0.96 & 0.26 \\
\hline & & & & P int & 0.71 \\
\hline \multirow[t]{3}{*}{$\mathrm{MAP}^{\mathrm{a}}$} & $\mathrm{CRF}(\mathrm{ml} / \mathrm{kg} / \mathrm{min})$ & -2.84 & 0.0002 & -1.94 & 0.03 \\
\hline & BMI $\left(\mathrm{kg} / \mathrm{m}^{2}\right)$ & 2.69 & 0.0005 & 1.58 & 0.08 \\
\hline & & & & $P$ int & 0.76 \\
\hline \multicolumn{6}{|l|}{ Men, $n=155$} \\
\hline \multirow[t]{3}{*}{ Systolic blood pressure } & $\mathrm{CRF}(\mathrm{ml} / \mathrm{kg} / \mathrm{min})$ & -2.55 & 0.02 & -0.62 & 0.66 \\
\hline & $\operatorname{BMI}\left(\mathrm{kg} / \mathrm{m}^{2}\right)$ & 3.37 & 0.002 & 2.98 & 0.03 \\
\hline & & & & P int & 0.51 \\
\hline \multirow[t]{3}{*}{ Diastolic blood pressure } & $\mathrm{CRF}(\mathrm{ml} / \mathrm{kg} / \mathrm{min})$ & -1.90 & 0.009 & -1.12 & 0.23 \\
\hline & BMI $\left(\mathrm{kg} / \mathrm{m}^{2}\right)$ & 1.91 & 0.008 & 1.20 & 0.19 \\
\hline & & & & P int & 0.70 \\
\hline \multirow[t]{3}{*}{$\mathrm{MAP}^{\mathrm{a}}$} & $\mathrm{CRF}(\mathrm{ml} / \mathrm{kg} / \mathrm{min})$ & -2.12 & 0.007 & -0.96 & 0.34 \\
\hline & BMI $\left(\mathrm{kg} / \mathrm{m}^{2}\right)$ & 2.40 & 0.002 & 1.80 & 0.07 \\
\hline & & & & $P$ int & 0.95 \\
\hline
\end{tabular}

${ }^{\mathrm{a}}$ MAP, mean arterial pressure $=[($ Diastolic blood pressure $* 2)+$ Systolic blood pressure $] / 3$.

${ }^{\mathrm{b}} \mathrm{BMI}$, body mass index. ${ }^{\mathrm{C}} \mathrm{CRF}$, cardiorespiratory fitness.

${ }^{\mathrm{d}}$ Model 1 Age-adjusted.

${ }^{\mathrm{e}}$ Model 2 Included age, CRF and Body Mass Index (BMI).

$P$ int $=\mathrm{p}$ value for interaction between BMI and CRF.

Table 3. Systolic and diastolic blood pressure and $\mathrm{MAP}^{\mathrm{a}}$ according to $\mathrm{BMI}^{\mathrm{b}}$ and $\mathrm{CRF}^{\mathrm{c}}$. Mean $\left(\mathrm{SD}^{\mathrm{d}}\right)$, the Tromsø Activity Study.

\begin{tabular}{|c|c|c|c|c|c|c|c|c|}
\hline & \multicolumn{4}{|c|}{ BMI $<25 \mathrm{~kg} / \mathrm{m}^{2}$} & \multicolumn{4}{|c|}{$\mathrm{BMI} \geq 25 \mathrm{~kg} / \mathrm{m}^{2}$} \\
\hline & CRF I & CRF II & CRF III & $\mathrm{P}$ trend & CRF I & CRF II & CRF III & $\mathrm{P}$ trend \\
\hline Men, $\mathbf{n}$ & 4 & 19 & 33 & & 48 & 33 & 18 & \\
\hline Diastolic bp, $\mathrm{mm} \mathrm{Hg}$ & $\begin{array}{c}73.3 \\
(9.46)\end{array}$ & $\begin{array}{c}73.9 \\
(8.22)\end{array}$ & $\begin{array}{c}74.8 \\
(6.36)\end{array}$ & 0.62 & $\begin{array}{c}80.2 \\
(9.45)\end{array}$ & $\begin{array}{c}75.3 \\
(9.57)\end{array}$ & $\begin{array}{c}75.1 \\
(8.36)\end{array}$ & 0.02 \\
\hline Systolic bp, mm Hg & $\begin{array}{l}117.8 \\
(11.8)\end{array}$ & $\begin{array}{l}120.4 \\
(12.2)\end{array}$ & $\begin{array}{l}122.5 \\
(13.2)\end{array}$ & 0.40 & $\begin{array}{l}129.0 \\
(14.6)\end{array}$ & $\begin{array}{l}122.6 \\
(12.9)\end{array}$ & $\begin{array}{l}122.6 \\
(12.3)\end{array}$ & 0.04 \\
\hline $\mathrm{MAP}^{\mathrm{a}}, \mathrm{mm} \mathrm{Hg}$ & $\begin{array}{c}88.1 \\
(9.33)\end{array}$ & $\begin{array}{c}89.4 \\
(8.71)\end{array}$ & $\begin{array}{c}90.7 \\
(8.01)\end{array}$ & 0.47 & $\begin{array}{c}96.5 \\
(10.3)\end{array}$ & $\begin{array}{c}91.0 \\
(10.1)\end{array}$ & $\begin{array}{c}90.9 \\
(8.50)\end{array}$ & 0.02 \\
\hline Women, $n$ & 15 & 30 & 40 & & 38 & 24 & 11 & \\
\hline Diastolic bp, mm Hg & $\begin{array}{c}75.7 \\
(6.95)\end{array}$ & $\begin{array}{c}69.2 \\
(9.44)\end{array}$ & $\begin{array}{c}67.9 \\
(7.42)\end{array}$ & 0.005 & $\begin{array}{c}73.8 \\
(8.09)\end{array}$ & $\begin{array}{c}72.4 \\
(10.4)\end{array}$ & $\begin{array}{c}71.5 \\
(9.89)\end{array}$ & 0.41 \\
\hline Systolic bp, mm Hg & $\begin{array}{l}118.1 \\
(15.3)\end{array}$ & $\begin{array}{l}114.9 \\
(11.5)\end{array}$ & $\begin{array}{l}109.5 \\
(10.1)\end{array}$ & 0.008 & $\begin{array}{l}118.4 \\
(13.6)\end{array}$ & $\begin{array}{l}120.4 \\
(15.0)\end{array}$ & $\begin{array}{l}114.5 \\
(16.7)\end{array}$ & 0.65 \\
\hline $\mathrm{MAP}^{\mathrm{a}}, \mathrm{mm} \mathrm{Hg}$ & $\begin{array}{c}89.8 \\
(9.32)\end{array}$ & $\begin{array}{c}84.4 \\
(9.15)\end{array}$ & $\begin{array}{c}81.8 \\
(7.72)\end{array}$ & 0.003 & $\begin{array}{c}88.6 \\
(9.36)\end{array}$ & $\begin{array}{c}88.4 \\
(11.2)\end{array}$ & $\begin{array}{c}85.8 \\
(11.9) \\
\end{array}$ & 0.49 \\
\hline
\end{tabular}

${ }^{a}$ MAP, mean arterial pressure $=[($ Diastolic blood pressure $* 2)+$ Systolic blood pressure $] / 3$.

${ }^{\mathrm{c}} \mathrm{CRF}$, cardiorespiratory fitness. ${ }^{\mathrm{b}} \mathrm{BMI}$, body mass index.

${ }^{\mathrm{d}} \mathrm{SD}=$ standard deviation. Numbers may vary due to missing information.

Cardiovascular fitness level was categorized in CRF I, low fitness $=\mathrm{VO} 2 \max <32.4 \mathrm{ml} / \mathrm{kg} / \mathrm{min}$ for women and $<39.6 \mathrm{ml} / \mathrm{kg} / \mathrm{min}$ for men; CRF II, medium fitness =VO2 $\max 32.4-37.5 \mathrm{ml} / \mathrm{kg} / \mathrm{min}$ for women and 39.6-46.5 $\mathrm{ml} / \mathrm{kg} / \mathrm{min}$ for men, and CRF III, high fitness $=\mathrm{VO} 2 \mathrm{max}>37.5 \mathrm{ml} / \mathrm{kg} / \mathrm{min}$ for women and $>46.5$ for men . 
and improved CRF are associated with lower risk of hypertension independently of other risk factors $(27,28)$. Blair et al. (6) reported persons with low physical fitness to have a relative risk of 1.5 for the development of hypertension when compared with highly fit persons. Sawada et al. (29) supported these findings in Japanese men as they observed the relative risk of hypertension to be 1.9 times higher in the least fit compared with the more fit group. Prospective studies have observed that higher level of physical activity is related to reduced risk for hypertension in men $(6,30,31)$, but not in women $(30,32)$.

We found CRF to be negatively associated with blood pressure, both among men and women. Our results are in accordance with results from clinical trials $(18,33)$ and cross-sectional studies, which have shown that physical activity is inversely associated with blood pressure (34), and that more fit subjects have lower blood pressure levels than less fit subjects (35). Additionally, in a meta-analysis including only randomized controlled trials, subjects fulfilling chronic dynamic aerobic endurance training are able to reduce their blood pressure (17).

Obesity is a major independent risk factor for hypertension $(13,36)$. Results from our previous studies using repeated assessments in the Tromsø study (12) showed that both BMI at baseline, and change in BMI, were independent predictors of changes in systolic and diastolic blood pressure in women. For a given BMI increase, obese women had a greater systolic and diastolic blood pressure increase than lean women. In men, blood pressure change was associated with BMI change, but the blood pressure increase was independent of the BMI value at baseline (12).

In a recent publication by Fogelholm (37), he importantly asked whether the obesity-fitness interaction was related to what extent physical activity or physical fitness counterbalance health risks associated with obesity? The main findings in his review of the area were that subjects with a high BMI, combined with a high physical activity level, were at greater risk of type 2 diabetes, of cardiovascular disease and type 2 diabetes risk factors, compared with subjects having a normal BMI and low physical activity level (37). In contrast, two other reviews suggest that good aerobic fitness, and perhaps also high physical activity, may be even more important for cardiovascular health than avoiding obesity $(38,39)$. The Cooper Center Longitudinal Study observed that only modest fitness levels among normal weighted individuals were associated with the lowest blood pressure estimates (40). In the HYPGENE study Rankinen et al. (7) found CRF to be a significant predictor of the risk of hypertension whereas in our study, BMI seemed to be a more important factor than CRF in predicting systolic blood pressure. Chen et al. (40) observed BMI to be more important than CRF in predicting systolic blood pressure only in the overweight range, in both men and women, which support our results (Figure 2).
We observed more men than women to be prehypertensive (56\% and $33 \%$, respectively) and only men in our study were on antihypertensive medication. The use of antihypertensive medication can affect our results, but when we excluded the seven men $(5 \%)$ who were users of antihypertensive medication, this did not change our results (results not presented in tables).

Additionally, CRF was negatively related to blood pressure among overweight and obese men (BMI $\geq 25$ $\mathrm{kg} / \mathrm{m}^{2}$ ), whereas CRF was negatively related to blood pressure among lean and normal weighted women (BMI $<25 \mathrm{~kg} / \mathrm{m}^{2}$ ). Our small number of participants (n =313) makes subgroup analyses challenging, and any conclusions need to be balanced.

This study has strengths and limitations. The Troms $\varnothing$ Study has a very high attendance rate (80\%) even throughout repeated assessments during 30 years, and the study design has been evaluated throughout these years (41). Another strength of our study is the objective measurement of CRF assessed by two trained persons. Maximum oxygen uptake $\left(\mathrm{VO}_{2} \mathrm{max}\right)$, which we assessed in this study, is regarded as the "gold standard" for the assessment of cardiovascular fitness. CRF reflects recent physical activity patterns, and it is a better method than self-reported assessments. However, participation in the Tromsø Activity Study may be influenced by the participants' rating of their own fitness, as fit individuals may be more likely to attend such a study compared to unfit individuals. This possible selection bias would influence the results if the associations of interest differ between those who attended and those who did not attend. Another possible weakness is the difference in time points of measurements for the main variables in the study; anthropometric variables and blood pressure were measured in the screening survey and CRF was measured in the Tromsø Activity Study. Mean time interval between these measurements was 3.2 months. However, inclusion of the time interval as a cofactor in the models did not change our results. Importantly, previous reports from the Tromsø study support a strong tracking of these variables among individuals followed for years with repeated assessments (42).

\section{CONCLUSion}

Among the healthy 40-44 year old men and women participating in this study, we found that high fitness was more often observed among lean/normal weighted compared to overweight/obese men and women. In age-adjusted analyses, both BMI and CRF were associated with blood pressure. When comparing BMI and $\mathrm{CRF}$ and their associations to blood pressure, BMI seemed to be a more important factor than CRF in predicting systolic blood pressure among both sexes, while CRF predicted diastolic blood pressure and MAP among women. Physical activity and CRF may both be important targets for prevention of hypertension. 


\section{ACKNOWLEDGEMENT}

The authors thank all the participants in the Tromsø Activity Study, Sissel Andersen and the Department of Community Medicine, University of Tromsø, for assistance with organization, the test lab at the University of Tromsø for testing facilities, and the testers Jorid Degerstrøm and Svein Arne
Pettersen. We are thankful to the Norwegian School of Sport Science for sharing information from the KAN1 study. The study is supported by the South-Eastern Norway Regional Health Authority, the Norwegian Research Council and the Norwegian Cancer Society (grant 05087 and TP 49 258). No conflict of interest.

\section{REFERENCES}

1. Hajjar I, Kotchen TA. Trends in prevalence, awareness, treatment, and control of hypertension in the United States, 1988-2000. JAMA 2003; 290 (2): 199-206.

2. Erdine S, Aran SN. Current status of hypertension control around the world. Clin Exp Hypertens 2004; 26 (78): 731-738.

3. Emaus A, Veierød MB, Tretli S, Finstad SE, Selmer R, Furberg AS, et al. Metabolic profile, physical activity, and mortality in breast cancer patients. Breast Cancer Res Treat 2010; 121 (3): 651-660.

4. Barengo NC, Hu G, Kastarinen M, Lakka TA, Pekkarinen H, Nissinen A, et al. Low physical activity as a predictor for antihypertensive drug treatment in 25-64-year-old populations in eastern and south-western Finland. J Hypertens 2005; 23 (2): 293-299.

5. Barlow CE, LaMonte MJ, Fitzgerald SJ, Kampert JB, Perrin JL, Blair SN. Cardiorespiratory fitness is an independent predictor of hypertension incidence among initially normotensive healthy women. Am J Epidemiol 2006; 163 (2): 142-150.

6. Blair SN, Goodyear NN, Gibbons LW, Cooper KH. Physical fitness and incidence of hypertension in healthy normotensive men and women. JAMA 1984; 252 (4): 487-490.

7. Rankinen T, Church TS, Rice T, Bouchard C, Blair SN. Cardiorespiratory fitness, BMI, and risk of hypertension: the HYPGENE study. Med Sci Sports Exerc 2007; 39 (10): 1687-1692.

8. Fagard RH. Exercise is good for your blood pressure: effects of endurance training and resistance training. Clin Exp Pharmacol Physiol 2006; 33 (9): 853-856.

9. Huang Z, Willett WC, Manson JE, Rosner B, Stampfer MJ, Speizer FE, et al. Body weight, weight change, and risk for hypertension in women. Ann Intern Med 1998; 128 (2): 81-88.

10. Gelber RP, Gaziano JM, Manson JE, Buring JE, Sesso HD. A prospective study of body mass index and the risk of developing hypertension in men. Am J Hypertens 2007; 20 (4): 370-377.

11. Guh DP, Zhang W, Bansback N, Amarsi Z, Birmingham CL, Anis AH. The incidence of co-morbidities related to obesity and overweight: a systematic review and meta-analysis. BMC Public Health 2009; 9: 88.

12. Wilsgaard T, Schirmer H, Arnesen E. Impact of body weight on blood pressure with a focus on sex differences: the Tromsø Study, 1986-1995. Arch Intern Med 2000; 160 (18): 2847-2853.

13. Kotchen TA. Obesity-related hypertension: epidemiology, pathophysiology, and clinical management. Am J Hypertens 2010; 23: 170-1178.

14. Hill JO, Melanson EL. Overview of the determinants of overweight and obesity: current evidence and research issues. Med Sci Sports Exerc 1999; 31 (11 Suppl): S515-S521.

15. Jebb SA, Moore MS. Contribution of a sedentary lifestyle and inactivity to the etiology of overweight and obesity: current evidence and research issues. Med Sci Sports Exerc 1999; 31 (11 Suppl): S534-S541.

16. Shaw K, Gennat H, O'Rourke P, Del MC. Exercise for overweight or obesity. Cochrane Database Syst Rev 2006; (4): CD003817.

17. Pescatello LS, Franklin BA, Fagard R, Farquhar WB, Kelley GA, Ray CA. American College of Sports Medicine position stand. Exercise and hypertension. Med Sci Sports Exerc 2004; 36 (3): 533-553.

18. Whelton SP, Chin A, Xin X, He J. Effect of aerobic exercise on blood pressure: a meta-analysis of randomized, controlled trials. Ann Intern Med 2002; 136 (7): 493-503.

19. Grundy SM, Blackburn G, Higgins M, Lauer R, Perri MG, Ryan D. Physical activity in the prevention and treatment of obesity and its comorbidities. Med Sci Sports Exerc 1999; 31 (11 Suppl): S502-S508.

20 Blair SN, Brodney S. Effects of physical inactivity and obesity on morbidity and mortality: current evidence and research issues. Med Sci Sports Exerc 1999; 31 (11 Suppl): S646-S662.

21. Emaus A, Degerstrøm J, Wilsgaard T, Hansen B, Dieli-Conwright C, Furberg AS, et al. Does a variation in self-reported physical activity reflect variation in objectively measured physical activity, resting heart rate and physical fitness? Results from the Tromsø Study. Scand J Public Health 2010; 38 (Suppl 5): 105-118.

22. Martinez-Gonzalez MA, Martinez JA, Hu FB, Gibney MJ, Kearney J. Physical inactivity, sedentary lifestyle and obesity in the European Union. Int J Obes Relat Metab Disord 1999; 23 (11): 1192-1201. 
23. Dwyer T, Hosmer D, Hosmer T, Venn AJ, Blizzard CL, Granger RH, et al. The inverse relationship between number of steps per day and obesity in a population-based sample: the AusDiab study. Int J Obes (Lond) 2007; 31 (5): 797-804.

24. Martinez JA, Kearney JM, Kafatos A, Paquet S, Martinez-Gonzalez MA. Variables independently associated with self-reported obesity in the European Union. Public Health Nutr 1999; 2 (1A): 125-133.

25. Stein CJ, Colditz GA. The epidemic of obesity. J Clin Endocrinol Metab 2004; 89 (6): 2522-2525.

26. Lee DC, Sui X, Blair SN. Does physical activity ameliorate the health hazards of obesity? Br J Sports Med 2009; 43 (1): 49-51.

27. Hu G, Barengo NC, Tuomilehto J, Lakka TA, Nissinen A, Jousilahti P. Relationship of physical activity and body mass index to the risk of hypertension: a prospective study in Finland. Hypertension 2004; 43 (1): 25-30.

28. Chase NL, Sui X, Lee DC, Blair SN. The association of cardiorespiratory fitness and physical activity with incidence of hypertension in men. Am J Hypertens 2009; 22 (4): 417-424.

29. Sawada S, Tanaka H, Funakoshi M, Shindo M, Kono S, Ishiko T. Five year prospective study on blood pressure and maximal oxygen uptake. Clin Exp Pharmacol Physiol 1993; 20 (7-8): 483-487.

30. Haapanen N, Miilunpalo S, Vuori I, Oja P, Pasanen M. Association of leisure time physical activity with the risk of coronary heart disease, hypertension and diabetes in middle-aged men and women. Int J Epidemiol 1997; 26 (4): 739-747.

31. Paffenbarger RS Jr, Wing AL, Hyde RT, Jung DL. Physical activity and incidence of hypertension in college alumni. Am J Epidemiol 1983; 117 (3): 245-257.

32. Pereira MA, Folsom AR, McGovern PG, Carpenter M, Arnett DK, Liao D, et al. Physical activity and incident hypertension in black and white adults: the Atherosclerosis Risk in Communities Study. Prev Med 1999; 28 (3): 304-312.

33. Kelley GA, Kelley KA, Tran ZV. Aerobic exercise and resting blood pressure: a meta-analytic review of randomized, controlled trials. Prev Cardiol 2001; 4 (2): 73-80.

34. Hu G, Tian H. A comparison of dietary and non-dietary factors of hypertension and normal blood pressure in a Chinese population. J Hum Hypertens 2001; 15 (7): 487-493.

35. Fagard RH. Physical activity, physical fitness and the incidence of hypertension. J Hypertens $2005 ; 23$ (2): 265-267.

36. de SG, Devereux RB, Chinali M, Roman MJ, Best LG, Welty TK, et al. Risk factors for arterial hypertension in adults with initial optimal blood pressure: the Strong Heart Study. Hypertension 2006; 47 (2): 162-167.

37. Fogelholm M. Physical activity, fitness and fatness: relations to mortality, morbidity and disease risk factors. A systematic review. Obes Rev 2010; 11 (3): 202-221.

38. Gill JM, Malkova D. Physical activity, fitness and cardiovascular disease risk in adults: interactions with insulin resistance and obesity. Clin Sci (Lond) 2006; 110 (4): 409-425.

39. Blair SN, Cheng Y, Holder JS. Is physical activity or physical fitness more important in defining health benefits? Med Sci Sports Exerc 2001; 33 (6 Suppl): S379-S399.

40. Chen J, Das S, Barlow CE, Grundy S, Lakoski SG. Fitness, fatness, and systolic blood pressure: data from the Cooper Center Longitudinal Study. Am Heart J 2010; 160 (1): 166-170.

41. Jacobsen BK, Eggen AE, Mathiesen EB, Wilsgaard T, Njølstad I. Cohort profile: The Tromsø Study. Int J Epidemiol 2011 (Epub ahead of print, doi:10.1093/ije/dyr049).

42. Wilsgaard T, Jacobsen BK, Schirmer H, Thune I, Løchen ML, Njølstad I, et al. Tracking of cardiovascular risk factors: the Tromsø study, 1979-1995. Am J Epidemiol 2001; 154 (5): 418-426. 